\title{
PENGARUH BUDAYA TULIS MENULIS PENDUDUK MADINAH TERHADAP PERKEMBANGAN PENULISAN HADIS
}

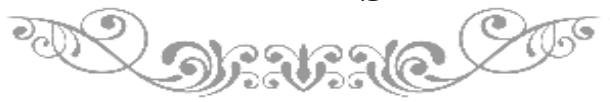

\section{Yor Hananta}

UIN Sunan Kalijaga Yogyakarta Email: yorperson@gmail.com

\begin{abstract}
The purpose of writing this article is to describe the cultural influence of writing the inhabitants of Medina on the development of Hadith during the hijra of the Prophet. As it is known to the general public that Medina became the center of Islamic civilization that exerted significant influence in advancing Islam to establish a sovereign state. This study is qualitative research, data obtained from library sources, and analysis conducted using descriptive analysis to obtain an overview of the purpose of this study. The results of the study obtained in this article illustrate the extent of the cultural development of the inhabitants of Medina, especially the Arabs, the development of Hadith during hijra, and the relationship between the culture of the writings of the inhabitants of Medina to the development of Hadith. The findings obtained in this article describe the culture of writings of the inhabitants of Medina, the development of Hadith that occurred in this period is in the increasing spread of Hadith in quality and quantity through oral intermediaries. The latest finding is that there is no significant link between the writing culture of the inhabitants of Medina and the development of Hadiths that occur in it against the backdrop of the brlakang presented in the results and discussion of the article.
\end{abstract}

Keywords: Hadith Writing; Writing Culture; Medina Islam

\begin{abstract}
Abstrak
Tujuan penulisan artikel ini adalah untuk menggambarkan pengaruh budaya tulis menulis Penduduk Madinah terhadap perkembangan hadis pada masa hijrah Nabi. Sebagaimana diketahui khalayak umum bahwa Madinah menjadi pusat peradaban Islam yang memberi pengaruh signifikan dalam memajukan Islam hingga membangun sebuah negara yang berdaulat. Kajian ini merupakan penelitian kualitatif, data yang
\end{abstract}


diperoleh dari sumber kepustakaan, dan analisis yang dilakukan menggunakan analisis deskriptif guna memperoleh gambaran yang menjadi tujuan penelitian ini. Hasil penelitian yang diperoleh dalam artikel ini menggambarkan sejauh mana perkembangan budaya tulis-menulis penduduk Madinah khususnya bangsa Arab, perkembangan hadis pada masa hijrah, dan hubungan antara budaya tulis-menulis penduduk Madinah terhadap perkembangan hadis. Temuan yang diperoleh dalam artikel ini menggambarkan bururknya budaya tulis-menulis penduduk Madinah, perkembangan hadis yang terjadi dalam kurun waktu ini ada pada peningkatan penyebaran hadis dalam kualitas dan kuantitas melalui perantara lisan. Temuan terakhir adalah tidak ditemukannya hubungan yang signifikan antara budaya tulis-menulis penduduk Madinah dengan perkembangan hadis yang terjadi di dalamnya dengan latar brlakang yang disajikan dalam hasil dan pembahasan artikel.

Kata Kunci: Penulisan Hadis; Budaya Tulis Menulis; Islam Madinah

\section{PENDAHULUAN}

Selama ini perhatian atas perkembangan budaya tulis menulis Islam Madinah sangat terbatas. Banyak ditemukan penelitan-penelitian tentang sejarah penulisan Hadis, akan tetapi Madinah sebagai periode dan lokal paling berpengaruh dalam perkembangan Islam kurang mendapat perhatian khusus. Diasumsikan bahwa pengaruh hijrah ke Madinah ini memberi pengaruh yang signifikan dalam perkembangan penulisan Hadis sehingga dapat sampai ke tangan muslim hari ini.

Alquran tidak mungkin diturunkan dalam ruang kosong, di mana tidak ada manusia, dan kebudayaan. Hal ini adalah konsekuensi logis dari tujuan penurunan Alquran, cara ia diturunkan, dan dengan bentuk seperti apa ia diturunkan. Masyarakat Mekah pada masa jahiliyah pada masa itu merupakan segolongan komunitas yang tidak mengenal tulis menulis. Hal ini disebabkan keadaan mereka yang terisolasi di wilayah pedalaman sebagaimana dijelaskan Abū Zahw bahwa kemampuan tulis menulis adalah salah satu pembeda antara masyarakat berperadaban dan badui. ${ }^{1}$

Keterbatasan kemampuan tulis menulis dalam kebudayaan Bahasa Arab ini menggambarkan rendahnya kebudayaan yang berkembang dalam masyarakat tersebut. Meski pun demikian, faktanya kekurangan ini justru menonjolkan suatu kelebihan masyarakat Mekah mengenai kemampuan hafalan yang tidak tertandingi sepanjang sejarah. Bahkan Abū Zahw

${ }^{1}$ Muhammad Abū Zahw, The Histori of Hadith, Historiografi Hadits Nabi dari Masa ke Masa (Depok: Keira Publishing, 2017), 106. 
menjelaskan bahwa tidak dikenalnya budaya tulis menulis ini kemudian mengharuskan mereka untuk terus mengasah kemampuan memori mereka untuk menghafal termasuk dalam penghimpunan data-data penting, seperti syair, garis nasab, moment um kebanggaan dan hari-hari penting. ${ }^{2}$

Turunnya Alquran dan dimulainya penyebaran ajaran Islam di Mekah tidak mengalami perkembangan yang siginifikan dengan latar belakang yang telah disebutkan. Akan tetapi hijrah kaum muslimin ketika itu ke Madinah memberi pengaruh yang signifikan dalam budaya tulis-menulis masyarakat Muslim hingga akhirnya hasilnya dapat kita nikmati pada masa ini. Bukan hanya dalam hal tulis menulis saja yang berkembang pada masa ini, melainkan juga perkembangan dalam pemerintahan, tatanan masyarakat, dan ajaran Islam yang lebih menyatu dengan kehidupan manusia.

Kekhasan dari perkembangan budaya tulis-menulis pada masa hijrah Madinah ini menjadi sorotan yang menarik dalam mempelajari geneologi pembukuan Hadis. Strategi-strategi yang digunakan untuk menyelesaikan problem-problem umat khususnya yang berkaitan dengan kodifikasi Hadis. Oleh karenanya dapat diwariskan menjadi harta warisan yang menjadi pedoman oleh umat muslim seluruh dunia hingga saat ini dan menjadi qiyās strategi dalam pengambangan peradaban yang tidak dimiliki oleh suatu masyarakat.

Kenyataan bahwa Nabi Muhammad adalah seorang yang 'umiy yang dipengaruhi latar belakang masyarakat Mekkah dan ketidak piawaiannya dalam membuat syair merupakan salah satu faktor yang menguatkan keotentikan Alquran, tidak dapat diragukan oleh outsiders atau pun insiders sendiri. Fakta ini kemudian mengarahkan para cendikiawan muslim untuk mempertanyakan bagaimana pengumpulan Alquran dan Hadis dapat dilakukan dengan keterbatasan sumber daya manusia atau pun fasilitas yang tidak memadai? Dari mana kemampuan tulis menulis ini berasal dan bagaimana kemampuan tulis menulis disebarkan hingga sampai pada masyarakat Mekah yang buta huruf?

Tujuan artikel ini adalah untuk menggambarkan keadaan budaya tulis menulis penduduk Madinah pada masa hijrah, mengetahui perkembangan tulis menulis Hadis sebelum dan sesudah hijrah ke Madinah, dan menggambarkan pengaruh budaya tulis menulis Madinah pada penulisan Hadis $^{3}$ 1) Kenapa budaya tulis-menulis penduduk Madinah memiliki urgensi dalam penulisan Hadis? 2) Apa karakteristik perkembangan Hadis di Madinah? 3) Bagaimana transformasi budaya tulis-menulis penduduk Madinah pada masa hijrah nabi?

${ }^{2}$ Muhammad Abū Zahw, The Histori of Hadit, 107.

${ }^{3}$ Saipul Hamdi, "Politik Islah: Re-Negosiasi Islah, Konflik, Dan Kekuasaan Dalam Nahdlatul Wathan Di Lombok Timur," Jurnal Kawistara 1, No. 1 (April 2011): 42, https://doi.org/10.22146/kawistara.3902. 
Dalam melakukan pengamatan, ditemukan literatur-literatur yang juga mengkaji tentang sejarah penulisan Hadis. Pada bagian ini akan dipaparkan studi-studi yang telah dilakukan beserta pernjelasan perbedaan fokus dan tujuan dari studi yang telah ada dengan yang akan dibahas dalam artikel ini. Tujuan-tujuan tersebut antara lain: Membuat sanggahan ilmiah terhadap berbagai pendapat inkar sunnah dikarenakan Nabi melarang penulisan tersebut, ${ }^{4}$ 2) Menggambarkan karakterisitk penulisan dan penyebaran Hadis sejak zaman Nabi hingga kodifikasi secara resmi, ${ }^{5}$ 3) Memberikan klarifikasi ilmiah terhadap tudingan yang ditujukan pada Sahabat terkait dusta dan kekurangan serta kualitas adil yang dinisbatkan pada mereka, ${ }^{6}$ 4) Memperkenalkan gagasan M. Mustafā A'zamī dan kritiknya tentang metodologi barat yang digunakan untuk menjustifikasi Hadis. ${ }^{7}$ 5) Mengkritisi metode kritik sejarah Ahmad Amīn yang digunakan untuk mengritik eksistensi dan sejarah Hadis menurut para ulama klasik. ${ }^{8}$

Berdasarkan tujuan dan fokus dari studi-studi terkait yang ditemukan tiga kategori penelitian berdasarkan karakteristik dan jenis penelitian. Pertama, studi yang berfokus untuk memberi klarifikasi atau sanggahan ilmiah terhadap pemikiran yang ada melalui sejarah Hadis. Kedua, Menggambarkan secara murni tentang sejarah penulisan Hadis dengan berbagai klasifikasi. Ketiga, Studi tokoh yang memiliki gagasan tentang kritik sejarah Hadis.

Adanya literatur-literatur sebelumnya yang telah mengkaji sisi kesejarahan Hadis memiliki karakteriktik berupa tujuan dan fokus yang berbeda sebagaimana telah dijelaskan sebelumnya. Kajian-kajian tersebut juga telah mengkaji dan menjawab berbagai isu-isu terkait kesejarahan Hadis yang dapat dijabarkan sebagai berikut; 1) menghapus keraguan dalam penulisan Hadis dan penggunaan Hadis sebagai sumber ilmu agama yang valid, 2) memenuhi kebutuhan akan alur sejarah penulisan Hadis secara runtut berdasarkan periode, ringkas dan padat, 3) memberi penjelasan terhadap tuduhan akan ke-' adil-an sahabat, 4) Menjawab tuduhan orientalis

${ }^{4}$ Suriani Sudi et al., "Sejarah Penulisan Hadis: Pembetulan Fakta dari Hujah Anti Hadis," dalam E-Proceeding of the 1st INHAD International Muzakarah \& Mu'tamar on Hadith, Kuala Lumpur, 25 April 2016, 7.

${ }^{5}$ Lukman Zain, "Sejarah Hadis Pada Masa Permulaan Dan Penghimpunannya," Diya Al-Afkar: Jurnal Studi al-Qur'an Dan al-Hadis 2, No. 01 (Juni 2014), https://doi.org/10.24235/diyaafkar.v2i01.564.

${ }^{6}$ Nurul Husna, "Sejarah Hadis Dan Problematika Sahabat," Al-Bukhānī: Jurnal Ilmu Hadis 1, No. 2 (2018): 267-80.

${ }^{7}$ Nurul Fitria Aprilia, "Hadis Nabawi dan Sejarah Kodifikasinya (Studi atas Pemikiran Prof. Dr. M. M. Azami)," Jurnal Al-Hikmah 7, No. 1 (Oktober 2019): 81-102.

${ }^{8}$ Ilham Ramadan Siregar, "Kritik Sejarah Terhadap Hadis Menurut Ahmad Amin: Analisis Terhadap Kitab Fajr al-Islam," AT-TAHDIS: Journal of Hadith Studies 1, No. 1 (Maret 2017), http://jurnal.uinsu.ac.id/index.php/attahdits/article/view/648. 
terhadap aspek sejarah Hadis dengan metodologi yang juga ilmiah, 5) Menggambarkan metodologi Ahmad Amin dipandang controversial karena meragukan kaidah kullu shahabat 'udul.

Dalam menjawab rumusan masalah pertama digunakan metode analisis deskriptif. Cakupan pada bagian ini adalah informasi tentang urgensi mengetahui budaya tulis-menulis penduduk Madinah. Hal ini meliputi gambaran etnografi, peradaban/pendidikan, dan interaksi sosial antar etnis atau pun agama yang memiliki pengaruh pada budaya tulismenulis penduduknya. Deskripsi Metode yang digunakan diterapkan dengan mendeskripsikan data-data yang diperoleh dari literatur-literatur yang diperoleh.

Dalam menjawab rumusan masalah kedua digunakan metode analisis deskriptif. Cakupan pada bagian ini adalah gambaran perkembangan Hadis mulai dari periode Mekah hingga Tabiin. Hal ini meliputi kondisi kelebihankelebihan apa saja yang diperoleh Nabi dan Umat muslim khususnya dalam hal penulisan Hadis. Deskripsi Metode yang digunakan diterapkan dengan mendeskripsikan data-data yang diperoleh dari literatur-literatur yang diperoleh dengan poin-poin yang memaparkan karakteristik penduduk Madinah dalam budaya tulis-menulis.

Dalam menjawab rumusan masalah ketiga digunakan metode analisis deskriptif analisis. Cakupan pada bagian ini adalah penggambaran analisis terhadap data-data yang telah terkumpul dalam bentuk pola-pola dan data yang telah disajikan. Hal ini meliputi hubungan antara budaya tulis-menulis penduduk Madinah dan perkembangan Hadis. Deskripsi Metode yang digunakan, diterapkan dengan mendeskripsikan data-data yang diperoleh dari literatur-literatur yang diperoleh guna memperoleh gambaran hubungan budaya tulis menulis penduduk Madinah dan perkembangan Hadis sebelum masuk era șahạābah dan tābi'īn.

\section{PEMBAHASAN}

Madinah memiliki beberapa nama, dulunya bernama Yathrib sebelum Nabi hijrah dari Mekah lalu menamainya dengan Madinah alMunawwarah (Kota yang Bersinar) dan pada kesempatan lain menyebutnya dengan Țayyibah. ${ }^{9}$ Nama Madinah sendiri memiliki arti yang menunjukkan tempat yang ditempati dan dibangun peradaban di atasnya. Menurut ahli sejarah nama Yathrib diambil dari nama pendiri kota ini yaitu salah satu

${ }^{9}$ Madinah memiliki beberapa nama yang menunjukkan bahwa kota ini memiliki derajat yang tinggi. Para ahli sejarah menyatakan ada seratus nama yang dinisbatkan pada kota ini, ada pula yang menyatakan sejumlah dua puluh sembilan nama, sedangkan dalam Hadis sahịh hanya ditemukan enam nama yang merujuk pada kota ini. Nama-nama lainnya antara lain Țābah, al-Maḥabbah, al-Maḥbūb, al-Najiyah, al-Mubārakah, al-Mujannah, alMarzūqah, al-Shafiyah, al-Khayyirah, al-Marhumah, al-Mahfūfah, al-Qudsiyyah, Dār alHijrah, dan al-Jabirah. Shawqi Abū Khalil, Atlas Hadits, Uraian Lengkap Seputar Nama, Tempat, dan Kaum yang Disabdakan Rasulullah (Jakarta Timur: Almahira, 2009), 332. 
keturunan Nabi Nūḥ As. dari generasi keenam-informasi lain menyatakan kedelapan. Ia memimpin sebuah kabilah bernama A'bil. Dari waktu ke waktu kota ini didatangi oleh banyak imigran secara individu atau pun kelompok. Di antara bangsa-bangsa yang datang ke Yathrib adalah; 1) Bangsa Amaliq, mereka mendirikan perkebunan dan berhasil melakukan pengembangan di Madinah, 2) Bangsa Yahudi, pada tahun 589 SM mereka berimigrasi ke Yathrib karena diusir oleh Nebukadnezar (Bukhtanașșor), 3) Bangsa Yahudi Bani Quraizah, Bani Nazir, dan Bani Qaynuqa' datang dan banyak melakukan aktivitas perkebunan sesuai keahlian mereka, 4) Kabilah Aus dan Khadraj mengungsi ke Madinah ketika bendungan Ma'arib di Yaman runtuh. ${ }^{10}$

\section{Urgensi Budaya Tulis-Menulis Penduduk Madinah dalam Perkembangan Hadis}

Dalam menyajikan data-data yang diperlukan untuk melakukan kajian terhadap budaya tulis-menulis Madinah, diperlukan penyajian beberapa aspek dalam sosial-budaya penduduk Madinah. Aspek-aspek ini meliputi etnografi, budaya, ${ }^{11}$ praktik interaksi sosial penduduk Madinah. ${ }^{12}$

Pertama, aspek etnografi penduduk Madinah pada masa Hijrah. Pada bagian ini disajikan data-data yang berkaitan dengan etnis yang menempati Madinah pada masa hijrah beserta formasi masing-masing etnis dalam tatanan masyarakat penduduk Madinah. Kondisi sosial Yathrib pada masa sebelum Nabi hijrah berada dalam keadaan naturalis dengan konsep 'manusia sebagai serigala bagi yang lain' dan berkembang hingga sampai pada tahap 'perang semua melawan semua'. Pada masa ini Yathrib dihadapkan dengan situasi perang saudara antara dua suku dominan di dalamnya. Kedua suku ini adalah suku 'Aws dan Khadraj yang diadu domba oleh beberapa suku Yahudi di kota itu. Situasi ini kemudian memaksa kedua suku tersebut untuk memilih Nabi untuk menjadi mediator dari pihak netral atas konflik yang terjadi. Sebelum Nabi datang untuk memenuhi panggilan kedua suku tersebut, ia memerintahkan Mus'ab bin Umayr, perwakilannya di Yathrib, untuk membuat perjanjian yang berhasil menghentikan perang dan permusuhan yang ada. Selang beberapa tahun kemudian persatuan dan

\footnotetext{
${ }^{10}$ Mereka kemudian dipekerjakan oleh orang-orang Yahudi karena orang orang dari kedua Kabilah ini memiliki keuletan dalam bekerja.

${ }^{11}$ Wa Ode Sifatu, "Perubahan, Kebudayaan, Dan Agama: Perspektif Antropologi Kekuasaan E-Jurnal Kajian Budaya (Online Journal of Cultural Studies)," 102, accessed January 3, 2020, https://ojs.unud.ac.id/index.php/kajian/article/view/13874.

12 Praktik yang dimaksud pada bagian ini adalah pengetahuan yang dipelajari atau diajarkan kepada orang lain sebagai anggota dari kategori sosial umum. Lihat Waltraud Kokot and I. Wayan Suyadnya, "Budaya dan Ruang - Pendekatan Antropologis," Jurnal Kajian Ruang Sosial-Budaya 2, No. 1 (Maret 2018): 167.
} 
kesatuan negara terwujud serta popularitas Nabi pun telah mewarnai seantero kota ini. Keadaan yang sudah kondusif ini menandakan bahwa sudah waktunya Nabi berhijrah dan penduduk Madinah pun menyambutnya sebagai pemimpin. ${ }^{13}$ Adapun yang terkenal paling jahat dari kaum Yahudi di tanah Arab adalah Bani Qaynuqa'. Al-Mubarakfüri kemudian membagi kelompok-kelompok yang ada di Madinah tersebut menjadi tiga golongan yaitu: para sahabat yang merupakan orang-orang pilihan, mulia dan ahli kebajikan; kaum musyrikin yang belum beriman sementara mereka berasal dari jantung Kabilah-kabilah di Madinah; dan rang-orang Yahudi. ${ }^{14}$

Kedua, aspek budaya dan pendidikan penduduk Madinah pada masa Hijrah. Dalam hal kebudayaan penduduk Madinah, piagam Madinah yang terdiri dari 47 pasal, disusun dengan inisiatif penduduk Madinah sendiri, dan ditetapkan sebagai hukum tertulis memberi gambaran tentang dalam budaya seperti apa mereka hidup. ${ }^{15}$ Budaya penduduk Madinah tentu saling berkaitan dengan pendidikan umat, terlebih dengan keleluasaan yang diperoleh umat Muslim di Madinah perkembangan pendidikan dan budaya pun tentu kian pesat. Dalam pendidikan Antonio mengategorikannya menjadi dua kelompok yaitu pendidikan untuk umat Islam secara keseluruhan dan anak secara khusus. ${ }^{16}$ Pendidikan umat secara umum maupun anak, keduanya menempatkan Masjid sebagai pusat pengembangannya. Pada masa kedudukan Nabi di Madinah, selain sebagai tempat ibadah Masjid dijadikan sebagai markas pemerintahan, tempat pendidikan, tempat pertemuan, dan pusat misi. Lebih lanjut masjid berkembang menjadi pusat pendidikan dan kampus yang memberi pengaruh terhadap peradaban Islam. Berkaitan dengan budaya tulis-menulis, al-Farūqi pun menyatakan bahwa budaya tulis menulis sudah dikenal oleh masyarakat Arab. Hal ini dibuktikan dengan temuan-temuan arekeologis berbentuk tulisan sederhana di atas prasasti dan lembaran papirus di jazirah Arab. Meski tulisan-tulisan yang sudah ada masih sangat sederhana, tetapi inilah yang menjadi pijakan dalam perkembangan penulisan Hadis. Meski demikian, praktik keterampilan ini tidak banyak dipraktikkan oleh orangorang pada zaman Nabi karena popularitas bersyair dan menghafal saat itu lebih kuat. ${ }^{17}$

Ketiga, aspek interaksi sosial antara penduduk Madinah pada masa hijrah. Dalam aspek ekonomi tercatat bahwasanya hubungan dagang

${ }_{13}$ Muhammad Syafi'i Antonio, Ensiklopedia Peradaban Islam Madinah (Jakarta Selatan: Tazkia Publishing, 2012), 214.

${ }^{14}$ Shafiyyurrahman al-Mubarakfuri and Hanif Yahya, Perjalanan Hidup Rasul yang Agung Muhammad Saw, Dari Kelahiran hingga Detik-detik Terakhir (Jakarta: Kantor Atase Agama Kerajaan Saudi Arabia, 2001), 255.

${ }^{15}$ Muhammad Syafi'i Antonio, Ensiklopedia Peradaban Islam Madinah, 218-23.

${ }^{16}$ Muhammad Syafi'i Antonio, Ensiklopedia Peradaban Islam Madinah, 217.

${ }^{17}$ Ismail Raji al-Faruqi and Lois Lamya al-Faruqi, Atlas Budaya Islam, Menjelajah Khazanah Peradaban Gemilang (Bandung: Mizan, 2003), 186. 
multilateral yang berlangsung selama hampir 2000 tahun telah menyimpan peradaban dan menyisakan berbagai aspek kemajuan politik, ekonomi, seni dan budaya. Adanya bendungan Ma'arib di kerajaan Saba' dan kerajaan Himyar di Yaman bagian selatan sebagai sumber air untuk wilayah kerajaan juga memberikan kesejahteraan bagi masyarakat terutama di sektor pertanian yang menjadi salah satu perekonomian penting mereka. Tercatat bahwa bangsa Arab telah mengenal alat pertanian semi modern seperti cangkul, alat bajak, kongkat kayu untuk menanam dan garu. Dalam menjalankan pertanian Bangsa Arab telah memiliki tiga sistem pertanian antara lain: sistem ijärah (sewa-menyewa), sistem muzära'ah (bagi hasil), dan system mudārabah (kongsi). ${ }^{18}$ Dijelaskan bahwa kemajuan kebudayaan dan peradaban bangsa Arab dapat mencapai taraf ini dilatar belakangi tiga interaksi yang terjadi di dalamnya, yaitu; 1) hubungan dagang dengan bangs lain, 2) melalui kerajaan protektorat di Ḥirah dan Ghassān, 3) masuknya misi Yahudi dan Nasrani. Adapun tentang industridan kerajinan Bangsa Arab sangat asing dengan hal tersebut. Para wanita Arab hanya bisa memintal sedangkan hasil kerajinan yang ada di Arab didatangkan dari Yaman, Ḥirah, dan pinggiran Syam. ${ }^{19}$

Pada masa sebelum hingga masa Hijrah pasar-pasar di Madinah dominan dikuasai kapitalis Yahudi. Oleh karenanya untuk dapat membangun persaingan yang sehat pasar-pasar tersebut Nabi membangun sebuah Masjid dan membuat pasar di sekitarnya untuk melakukan transaksi jual beli. Pada perkembangan selanjutnya, untuk menjaga kekhusyukan beribadah aktivitas jual beli tidak lagi dilakukan di sekitar masjid. Aktivitas jual beli ini kemudian dipindah ke $S \bar{u} q$ al-Ansār yang dikelola seratus persen oleh umat Islam. Dalam strategi ini Muslim dihimbau untuk melakukan transaksi jual beli dan aktivitas perdagangan di tempat tersebut dengan meninggalkan berbagai kerjasama dengan Yahudi dan tidak terlibat sedikit pun dengan segala produk mereka. Lama kelamaan roda perekonomian Yahudi yang sudah berjalan selama ratusan tahun gulung tikar dan akhirnya menutup pasar mereka. Hal ini ditujukan untuk dapat mencapai keseimbangan sosial. ${ }^{20}$ Prinsip dagang sebelum Islam masuk Madinah, muzābanah adalah membeli buah kurma basah dengan kurma kering yang masih $\mathrm{d}$ atas pohon. Muhaqalah adalah menyewakan kebun dengan pembayaran makanan (bahan makanan) dalam takaran yang ditentukan. Mukhäbarah adalah menyewakan kebun atau ladang dengan pembayaran $1 / 3$ atau $1 / 4$ hasil panennya. $M u$ 'awamah adalah menyewakan kebun buah selama beberapa tahun untuk

18 Muhammad Syafi'i Antonio, Ensiklopedia Peradaban Islam Madinah, 58-59.

19 Muhammad Syafi'i Antonio, Ensiklopedia Peradaban Islam Madinah, 60.

${ }^{20}$ Muhammad Syafi'i Antonio, Ensiklopedia Peradaban Islam Madinah, 61. 
dipungut buahnya. Kesemua prinsip ini dilarang oleh Nabi karena mengandung spekulasi. ${ }^{21}$

Ketiga aspek di atas membentuk sebuah tatanan masyarakat yang saling bekerja sama untuk hidup, meski pada kenyataannya pertumpahan darah tidak dapat dielakkan. Keberagaman etnis, agama, dan kelompok ini di satu sisi menyatukan akan tetapi di sisi lain juga menghancurkan satu sama lain.

\section{Karakteristik Perkembangan Hadis di Madinah}

Menurut 'Itr, dalam perkembangannya, Ilmu Hadis mengalami tujuh tahapan: Tahap kelahiran Ilmu Hadis; tahap penyempurnaan; tahap pembukuan Ilmu Hadis secara terpisah; tahap penyusunan kitab-kitab induk 'Ulüm al-Hadith; tahap kematangan dan kesempurnaan pembukuan 'Ulüm al-Hadith; masa kebekuan dan kejumudan; masa kebangkitan kedua. Dalam tahapan-tahapan ini, 'Itr menyatakan bahwa tahap kelahiran Ilmu Hadis dimulai pada masa sahabat sampai akhir abad pertama hijriah, dengan kesempurnaan hafalan Alquran yang tentu saja secara bersamaan dengan penguasaan dan pemeliharaan Hadis. ${ }^{22}$ Al-Bukhārì meriwayatkan sebuah Hadis dari Abu Hurayrah yang menyatakan tentang tidak adanya seorang pun dari sahabat Nabi yang meriwayatkan Hadis lebih banyak darinya (Abu Hurayrah) kecuali Abdullah bin 'Amr karena ia menulis dan aku (Abū Hurayrah) tidak" ${ }^{23}$ Ada pun riwayat Abū Dawud dari Abdullah bin Amr berkata bahwa ia menulis sabda-sabda Nabi untuk dihafalkan, akan tetapi orang-orang Quraysh melarangnya dengan pendapat bahwa Rasulullah saw. adalah manusia yang berkata dalam keadaan marah dan juga ramah. Maka ia pun mengadukan hal tersebut dan Nabi berkata, "Tulislah, demi Zat yang jiwaku dalam genggaman-Nya, tidak keluar dari lisanku kecuali hal-hal yang haq." 24 Menurut 'Itr bahwa ada kemungkinan pembolehan atau bahkan perintah penulisan Hadis ini memiliki beberapa sebab. Pertama, hanya dikhususkan untuk sahabat-sahabat tertentu yang mampu membaca kitabkitab terdahulu dan menulis dengan bahasa Suryani dan Arab. Kedua, Hadis pembolehan ini adalah nāsikh untuk Hadis larangan penulisan Hadis. Ketiga larangan ini hanya untuk penulisan Hadis bersamaan dengan Alquran dalam satu lembar. ${ }^{25}$ Boleh dikatakan tiada pencatat yang ditugaskan secara resmi untuk mencatat dan menghimpunkan Hadis melainkan ia dilakukan atas kehendak individu para sahabat sendiri. Oleh karenanya terdapat juga Hadis

\footnotetext{
${ }^{21}$ Muhammad Syafi'i Antonio, Ensiklopedia Peradaban Islam Madinah, 62.

${ }^{22}$ Nüruddin 'Itr. ${ }_{2}$ Ulumul Hadis (Bandung: Remaja Rosdakarya, 2017), 25.

${ }^{23}$ Bukhārī. Kitab al-'Ilm. Bab Kitābah al-'Ilm. No. Hadis 110

${ }^{24}$ Nüruddin 'Itr, Ulumul Hadis, 29.

25 Nūruddin 'Itr, Ulumul Hadis, 31.
} 
yang membuktikan bahwa Hadis itu ditulis pada zaman baginda s.a.w dan ia membuktikan bahwa Nabi Saw. membenarkan Hadis itu ditulis. ${ }^{26}$

Menurut 'Itr, terdapat beberapa dokumen Hadis yang telah ditulis pada zaman Nabi. Dokumen tersebut berbentuk lembaran-lembaran pribadi dan surat-surat Nabi sebagai pimpinan khilafah. Dokumen tersebut antara lain: al-Sahîfah al-Sädiqah, Saḥifah 'Ali bin Abì TTālib, Sahịifah Sa'ad bin Ubādah dan surat-surat Rasulullah. Dokumen pertama adalah karya 'Abdullāh bin 'Amr bin 'A $\bar{A}$ - seorang sahabat muhajirin-yang secara pribadi dibolehkan menulis Hadis dan diakui oleh Abū Hurayrah telah menghimpun lebih banyak Hadis darinya. Sahiffah yang kedua adalah dokumen tipis milik 'A $\bar{i}$ bin Abì Țâlib yang berisi Hadis tentang ketentuan hukum diat dan pembebasan tawanan. Dokumen ketiga miliki seorang sahabat senior dari kaum anshar Madinah yang dijadikan rujukan terhadap Hadis-Hadis riwayat Sa'ad. Ada pun dokumen terakhir adalah surat-surat Nabi yang dituliskan juru tulisnya pada masa beliau memerintah sebagai khalifah. ${ }^{27}$

\section{Budaya Tulis-Menulis Penduduk Madinah}

Dalam budaya tulis-menulis penduduk Madinah tidak terlalu berbeda jauh dengan budaya tulis-menulis di Mekah. Dari segi etnografi, Madinah memiliki penduduk yang lebih beragam dari pada penduduk Mekah. Keduanya sama-sama memiliki pasar sebagai tempat interaksi sosial dan transaksi ekonomi dilakukan. Pasar menjadi tempat para pendatang atau pun penduduk setempat melakukan interaksi, saling bertukar informasi dan barang. Bahkan pakaian berupa tutup kepala dan cadar sudah menjadi pakaian yang umum bagi semua orang bahkan bagi laki-laki. ${ }^{28}$ Keduanya juga sama-sama gemar berperang demi kehormatan kabilah mereka masingmasing. Akan tetapi dari kegemaran yang sama dalam berperang ini orangorang Madinah masih memiliki rasa lelah akan peperangan. Rasa frustasi ini kemudian mendesak mereka untuk menyelesaikan masalah yang ada. Kemungkinan keadaan heterogen dengan adanya kaum Yahudi di balik konflik mereka menjadikan peperangan yang ada hanya untuk kepentingankepentingan kelompok tertentu. Adapun dalam masyarakat Mekah yang homogen, mereka berperang berdasarkan kehormatan yang menjadi kebanggaan masing-masing kabilahnya. Hal ini ditunjukkan dengan adanya

${ }^{26}$ Sudi et al., "Sejarah Penulisan Hadis: Pembetulan Fakta dari Hujah Anti Hadis," 3.

${ }^{27}$ Nūruddin 'Itr, Ulumul Hadis, 35-37.

28 Mohammad Adnan, "Wajah Islam Priode Makkah-Madinah Dan Khulafaurrasyidin," Cendekia: Jurnal Studi Keislaman 5, No. 1 (Juni 2019): 6, https://ejurnal.staiha.ac.id/index.php/cendekia/article/view/74. 
kebingungan dari kabilah 'Aws dan Khazraj dalam menyelesaikan masalah mereka sendiri.

Kedatangan Nabi dengan membuat penawaran berupa Piagam Madinah menjadi sorotan dalam melihat sejauh mana penduduk Madinah pada masa hijrah Nabi mengenal budaya tulis-menulis. Sebelumnya dalam hasil penelitian disebutkan bahwa piagam Madinah memiliki catatan tertulis dengan jumlah pasal sebanyak 47 pasal yang mengatur seluruh kehidupan penduduk Madinah agar dapat hidup secara damai. Pembuatan pasal-pasal ini dilakukan dengan inisiatif dari mereka sendiri tanpa menggunakan rujukan dari peradaban lain yang lebih maju dalam hal perundang-undangan seperti Yunani dan Romawi, juga diperuntukkan bagi masyarakat luas di seluruh Madinah. Hal ini menggambarkan bahwa penduduk Madinah dalam hal pendidikan dan budaya tulis-menulis lebih mampu dari penduduk Mekah. ${ }^{29}$ Akan tetapi fakta tentang perang Badar yang mengharuskan setiap tawanan dari Quraysh Mekah mengajarkan sepuluh orang anak mengindikasikan hal yang berbeda. Bahwa penduduk Madinah tidak lebih baik dari penduduk Mekah dalam hal tulis-menulis. Dari dua kemungkinan yang ada ini, penulis lebih cenderung pada kemungkinan kedua dengan pendapat bahwa penulisan Hadis dalam sebuah naskah pribadi dan dikenal oleh umat Islam hari ini sebagian besar adalah kaum muhajirin. ${ }^{30}$

Sisi kebudayaan dan pendidikan Madinah memiliki keunggulan dari pada Mekah. Dari paparan data yang telah disebutkan, Madinah memiliki karakter budaya yang lebih terbuka dibanding Mekah. Ajaran agama baru atau di luar keyakinan mereka-terlebih lagi ajaran tersebut memiliki pengaruh kuat-tentu tidak akan diterima oleh masyarakatnya, sebagaimana dakwah Nabi kepada mereka. Hal serupa berbeda dengan kebudayaan Madinah, setiap kelompok diterima meski mereka memiliki keyakinan, norma, dan kemauan untuk bekerja dan mau membaur dengan masyarakat setempat, sebagaimana masuknya Yahudi dari beberapa gelombang dan suku-suku yang berbeda. Budaya yang inklusif ini juga berpengaruh terhadap kondisi pendidikan penduduk Madinah. Dengan adanya budaya semacam ini, segala sesuatu yang bersifat baik, benar, dan memberi keamanan bagi seluruh penduduknya dapat diterima tanpa memandang dari mana ia datang. Salah satu hal yang mengindikasikan hal ini adalah berdirinya Masjid Nabawi sebagai pusat pemerintahan kekhalifahan Islam dari Rasulullah Saw. sampai 'Ali bin Abì Țālib -meski pada masa kepemimpinan 'A $\mathrm{A}$, pusat pemerintahan dipindah ke Kufah-. Dari berdirinya masjid tersebut, peradaban dibangun melalui pendidikan umat secara umum, tempat pertemuan, dan pusat pelaksanaan misi. Berdirinya

${ }^{29}$ Khoirul Anwar, "Relasi Yahudi dan Nabi Muhammad di Madinah: Pengaruhnya Terhadap Politik Islam," Al-Ahkam 26, No. 2 (Desember 2016): 183, https://doi.org/10.21580/ahkam.2016.26.2.997.

${ }^{30}$ Nūruddin 'Itr, Ulumul Hadis, 255. 
satu masjid, yaitu Masjid Nabawi saja sudah memberikan banyak pengaruh terhadap kemajuan umat, terlebih terdapat beberapa masjid yang didirikan pada masa hijrah yaitu; Masjid Nabawi, Masjid Quba, Masjid Qiblatayn/Bani Salāmah, Masjid al-Rayyah -dibangun Abdullah bin Ubaidillah tempat penancapan bendera saat fathu al-Makkah (9 H.)-, Masjid Jin, Masjid Tan'im/masjid Aisyah $(9 \mathrm{H} \text {. })^{31}$

Kota-kota bangsa Arab selalu terkenal dengan pasar yang mereka miliki, begitu pun kota Madinah. Akan tetapi pengendali perekonomian dalam komunitas penduduk Madinah bukanlah bangsa Arab atau pun penduduk pribumi akan tetapi bangsa Yahudi. Mereka menguasai perekonomian pasar dengan permainan kapital mereka, sehingga penduduk lain selain bangsa Yahudi hanya menjadi konsumen atau pekerja kasar mereka. Pada bagian ini dijelaskan bahwa meski bangsa Yahudi datang dengan keahlian bertani mereka, tapi mereka pun punya keahlian dalam hal perekonomian, dan produksi barang sedangkan bangsa selain mereka tidak memiliki keahlian lain selain bertani dan perang. Oleh karena itu dalam hal perekonomian bangsa Arab terpuruk dan terjebak dalam sistem yang dibangun Yahudi. ${ }^{32}$ Dalam pandangan penulis, keadaan semacam ini menempatkan bangsa selain Yahudi menjadi bangsa kelas dua yang berperadaban rendah. Dengan dasar ini kemungkinan penduduk non-Yahudi yang memiliki keahlian di bidang-bidang keilmuan dan keterampilan sangatlah sedikit begitu juga yang memiliki kemampuan tulis-menulis yang nantinya berkontribusi terhadap penulisan Hadis.

\section{Karakteristik Perkembangan Hadis di Madinah}

Dalam perkembangan Hadis, masa kedudukan Madinah memiliki pengaruh yang signifikan. Hal ini dilatarbelakangi pusat kekuasaan yang berada dalam genggaman Islam. Aktivitas penentuan undang-undang, suratmenyurat, hubungan kerjasama dengan kaum Yahudi yang dari sebelumnya sudah banyak berkecimpung dengan tulis menulis, maupun aktivitasaktivitas kenegaraan lain yang melibatkan sabda Nabi dan penulisannya. Sebagaimana dijelaskan dalam sub-bagian sebelumnya aktivitas-aktivitas dakwah dalam bentuk pengajaran Alquran, majelis Rasulullah, kerjasama, dan surat-menyurat dengan leluasa dapat dilakukan. Sehingga kebebasan ini pun mendorong para sahabat untuk makin bersemangat dalam belajar dan mengajarkan Islam. Meski perkembangan Hadis khususnya dalam hal penulisan Hadis tidak terlalu mecolok, akan tetapi kegiatan lain berupa penghimpunan Hadis dalam hafalan sebagaimana yang dilakukan 'Umar bin

31 Abdurrahman bin Abdul Karim, Kitab Sejarah Nabi Muhammad SAW (Yogyakarta: Diva Press, 2013), 461.

32 Abdurrahman bin Abdul Karim, Kitab Sejarah Nabi Muhammad SAW, 465. 
Khaț̣āb dengan bergantian mengikuti majelis Rasulullah dengan tetangganya dan betuk-bentuk lainnya dapat dilaksanakan tanpa halangan apapun. Kegiatan tulis-menulis Hadis tidak terlalu menjadi fokus dan tidak mengalami perkembangan yang signifikan karena sebagian besar sahabat 'Umar bin Khaț̣āb masih memegang larangan Nabi untuk menulis Hadis dan kekhawatiran mereka terhadap keadaan di mana umat muslim melakukan kesalahan yang sama seperti orang-orang Yahudi yang terlalu sibuk dengan kitab-kitab karangan pembesar-pembesar mereka sampai lupa mempelajari kitab suci mereka.

\section{Transformasi Budaya Tulis-Menulis Penduduk Madinah Pada Masa Hijrah Nabi}

Telah dijelaskan dalam pembahasan sebelumnya tentang budaya tulis-menulis penduduk Madinah dan karakteristik perkembangan Hadis pada masa hijrah. Gambaran budaya tulis-menulis dan karakteristik perkembangan Hadis ini menjelaskan bagaiman kedua variabel ini saling berhubungan dan saling mempengaruhi. Naskah-naskah dan dokumen yang ditinggalkan para sahabat tidak mengindikasikan adanya pengaruh besar yang dipengaruhi budaya tulis-menulis penduduk Madinah dalam penulisan Hadis. Meski demikian perkembangan Hadis dalam hal penyampaian dan pertukaran perbendaharaan Hadis gencar dilakukan. Hal ini dapat dilakukan oleh para sahabat pada masa itu dilatarbelakangi kekusaan pemerintahan yang berada di pihak Nabi. Dari ketiga dokumen pribadi yang ditulis oleh tiga sahabat, hanya satu di antara mereka yang merupakan penduduk asli Madinah yaitu Sa'ad bin Ubādah dengan jumlah yang tidak banyak. Sedang dua dokumen lain adalah arsip pribadi sahabat dari kaum Muhajirin. Selain arsip-arsip pribadi tersebut, surat-surat kenegaraan yang ditulis berdasarkan sabda Nabi tidak dapat menggambarkan sejauh mana budaya tulis-menulis penduduk Madinah khususnya bangsa Arab sudah berkembang.

\section{SIMPULAN}

Artikel ini menemukan beberapa simpulan dalam mengamati informasi-informasi sejarah yang menjelaskan budaya tulis-menulis penduduk Madinah, perkembangan Hadis pada masa itu dan pengaruh yang dihasilkan dari budaya tulis-menulis penduduk Madinah terhadap perkembangan Hadis. Pertama, budaya tulis menulis penduduk Madinah khususnya bangsa Arab pada masa hijrah tidak dalam keadaan yang baik, didasarkan pada status sosial mereka, dokumen-dokumen yang ditemukan, dan keputusan tebusan untuk tawanan perang badar dengan mengajarkan baca tulis kepada penduduk Madinah. Kedua, perkembangan Hadis yang terjadi pada masa ini terjadi pada lingkup penyebaran Hadis, pertukaran perbendaharaan, dan penghimpunan Hadis-Hadis baru yang secara leluasa dapat disampaikan Nabi sebagai pemimpin Negara. Ketiga, tidak adanya 
hubungan yang signifikan antara budaya tulis-menulis penduduk Madinah terhadap perkembangan penulisan Hadis.

\section{DAFTAR PUSTAKA}

Abdul Karim, Abdurrahman bin. Kitab Sejarah Nabi Muhammad SAW. Yogyakarta: Diva Press, 2013.

Abū Khalil, Shawqi. Atlas Hadis, Uraian Lengkap Seputar Nama, Tempat, dan Kaum yang Disabdakan Rasulullah. Jakarta Timur: Almahira, 2009.

Abū Zahw, Muhammad. The Histori of Hadith, Historiografi Hadis Nabi dari Masa ke Masa. Depok: Keira Publishing, 2017.

Adnan, Mohammad. "Wajah Islam Priode Makkah-Madinah Dan Khulafaurrasyidin." Cendekia: Jurnal Studi Keislaman 5, No. 1 (Juni 2019). https://ejurnal.staiha.ac.id/index.php/cendekia/article/view/74.

Antonio, Muhammad Syafi'i. Ensiklopedia Peradaban Islam Madinah. Jakarta Selatan: Tazkia Publishing, 2012.

Anwar, Khoirul. "Relasi Yahudi dan Nabi Muhammad di Madinah: Pengaruhnya Terhadap Politik Islam." Al-Ahkam 26, No. 2 (Desember 2016):

179-202. https://doi.org/10.21580/ahkam.2016.26.2.997.

Aprilia, Nurul Fitria. "Hadis Nabawi dan Sejarah Kodifikasinya(Studi atas Pemikiran Prof. Dr. M. M. Azami).” Jurnal Al-Hikmah 7, No. 1 (Oktober 2019): 81-102.

Faruqi, Ismail Raji al-, and Lois Lamya al-Faruqi. Atlas Budaya Islam, Menjelajah Khazanah Peradaban Gemilang. Bandung: Mizan, 2003.

Hamdi, Saipul. "Politik Islah: Re-Negosiasi Islah, Konflik, Dan Kekuasaan Dalam Nahdlatul Wathan Di Lombok Timur." Jurnal Kawistara 1, No. 1 (April 2011). https://doi.org/10.22146/kawistara.3902.

Husna, Nurul. "Sejarah Hadis Dan Problematika Sahabat." Al-Bukhārī : Jurnal Ilmu Hadis 1, No. 2 (2018): 267-80.

'Itr, Nūruddin. Ulumul Hadis. Bandung: Remaja Rosdakarya, 2017.

Kokot, Waltraud, and I. Wayan Suyadnya. "Budaya dan Ruang Pendekatan Antropologis." Jurnal Kajian Ruang Sosial-Budaya 2, No. 1 (Maret 2018): 161-71.

Al-Mubārakfūri, Ṣafiyyurraḥmān, and Hanif Yahya. Perjalanan Hidup Rasul yang Agung Muhammad Saw, Dari Kelahiran hingga Detik-detik Terakhir. Jakarta: Kantor Atase Agama Kerajaan Saudi Arabia, 2001.

Sifatu, Wa Ode. "Perubahan, Kebudayaan, Dan Agama: Perspektif Antropologi Kekuasaan E-Jurnal Kajian Budaya (Online Journal of Cultural Studies)." Accessed January 3, 2020. https://ojs.unud.ac.id/index.php/kajian/article/view/13874. 
Siregar, Ilham Ramadan. "Kritik Sejarah Terhadap Hadis Menurut Ahmad Amin: Analisis Terhadap Kitab Fajr al-Islam." At-Tahdis: Journal of Hadith Studies 1, No. 1 (Maret 2017). http://jurnal.uinsu.ac.id/index.php/attahdits/article/view/648.

Sudi, Suriani, Rosni Wazir, Abūr Hamdi Usman, Mohd Norzi Nasir, Zanariah Ismail, Sakinah Salleh, and Azman Abdul Rahman. "Sejarah Penulisan Hadis: Pembetulan Fakta dari Hujah Anti Hadis." dalam E-Proceeding of the 1st INHAD International Muzakarah \& Mu'tamar on Hadith, Kuala Lumpur, 25 April 2016.

Zain, Lukman. "Sejarah Hadis Pada Masa Permulaan Dan Penghimpunannya." Diya Al-Afkar: Jurnal Studi al-Quran Dan alHadis 2, No. $01 \quad$ (Juni 2014). https://doi.org/10.24235/diyaafkar.v2i01.564. 